\title{
Modern contraceptive use and associated factors among married women in Finote Selam town Northwest Ethiopia: a community based cross-sectional study
}

Alehegn Bishaw Geremew* and Abebaw Addis Gelagay

\begin{abstract}
Background: A modern contraceptive method is a product or medical procedure that interferes with reproduction following sexual intercourse; however, contraceptive services remain out of reach for many women of reproductive age worldwide, resulting in millions of unwanted pregnancies and unsafe abortions each year. In addition to limiting the number of children, family planning is essential to promoting the well-being and autonomy of women, their families, and their communities. Factors influencing modern contraceptive utilization are multifaceted and challenging, therefore; this study aimed to assess modern contraceptive utilization and associated factors among mid to late reproductive age, married women in Finote Selam town, northwest Ethiopia.
\end{abstract}

Methods: A community based cross-sectional study was conducted from June 30 to July 15, 2017 among married women aged 30-49. A cluster sampling technique was used to select 1146 eligible participants from three randomly selected kebeles. A face-to-face interviewer administered a structured and pretested questionnaire. Binary logistic regression models, in bivariate and multivariable analyses, were fitted to identify factors associated with the outcome variable. Adjusted odds ratios (AOR) with 95\% confidence intervals (Cl) was calculated to determine the presence, direction, and strength of associations.

Results: A total of 1134 women aged 30-49 participated in this study representing a response rate of 98.9\%.The overall modern contraceptive utilization was $37 \%$ (95\% Cl 35.43-40.21). An injectable contraceptive was the most commonly used method, followed by an implant contraceptive method. Factors independently associated with modern contraceptive use were: educational status -secondary school ( $A O R=1.5,95 \% \mathrm{Cl} 1.01-2.2)$ and college and above (AOR $=1.5,95 \% \mathrm{Cl} 1.02-2)$ compared to no education, number of previous pregnancy: nulligravid ( $\mathrm{AOR}=4.6,95 \% \mathrm{Cl} 3.2-5.5)$, 1-2 previous pregnancies ( $\mathrm{AOR}=3.2,95 \% \mathrm{Cl} 2.03-5.44)$, 3-4 previous pregnancies $(\mathrm{AOR}=2.3,95 \% \mathrm{Cl} 1.4-3.7)$ compared to $>4$ pregnancies and postnatal care utilization $(\mathrm{AOR}=1.5,95 \% \mathrm{Cl} 1.1-2.1$ ) compared to no postnatal service utilized.

Conclusion: Our findings show that modern contraceptive utilization among women age 30-49 is low in Finote Selam town Northwest Ethiopia. Women's educational status, low number of previous pregnancies and postnatal care service utilization during the last birth were independently associated with modern contraceptive method used. Providing modern contraceptives targeting grand multiparous women and women having no formal education is important. Improving postnatal care utilization is one potential strategy to enhance modern contraceptive utilization.

Keywords: Modern contraceptive, Married women, Ethiopia

\footnotetext{
* Correspondence: alexbishaw@gmail.com

Department of Reproductive Health, Institute of Public Health, College of

Medicine and Health Science, University of Gondar, 196 Gondar, Ethiopia

(c) The Author(s). 2018 Open Access This article is distributed under the terms of the Creative Commons Attribution 4.0 International License (http://creativecommons.org/licenses/by/4.0/), which permits unrestricted use, distribution, and reproduction in any medium, provided you give appropriate credit to the original author(s) and the source, provide a link to the Creative Commons license, and indicate if changes were made. The Creative Commons Public Domain Dedication waiver (http://creativecommons.org/publicdomain/zero/1.0/) applies to the data made available in this article, unless otherwise stated.
} 


\section{Background}

Modern contraceptive methods are products or medical procedures that interfere with reproduction from the act of sexual intercourse [1]. In spite of progress on increasing modern contraceptive service utilization in recent years, contraceptive services remain out of reach for many women of reproductive age worldwide, resulting in millions of unwanted pregnancies and unsafe abortions each year [2]. In addition to limiting the number of children, family planning is essential to promoting the well-being and autonomy of women, their families and their communities [3]. Family planning services are one of the strategies for preventing more than $20 \%$ of maternal mortality and $17 \%$ of neonatal mortality [4].

In 2015 only $57 \%$ of married or in-union women of reproductive age used a modern method of family planning worldwide, with female sterilization (19\%) and Intra- Uterine Contraceptive Device (IUCD) (14\%) the most commonly used methods [5]. According to the 2016 Ethiopian Demographic Health Survey (EDHS), 35\% of currently married women used a modern contraceptive, 23\% used an injectable contraceptive and $8 \%$ an implant [6]. The factors that influence modern contraceptive utilization are multifaceted and challenging. Several studies provide evidence that modern contraceptive utilization is associated with socio-demographic, socio-cultural and economic factors, including women's educational status, monthly family income, women's empowerment, having attended four or more antenatal care visits, and knowledge of family planning [7-10]. Evidence from Nigeria suggests that modern contraception use among grand multiparty women is low and the main reason for non-use is the desire for more children [11]. However, contraceptive use among Human Papiloma virus(HIV) positive grand multiparous women is high [12].The proportion of modern contraceptive use among currently married reproductive age women in the Amhara region reported in the EDHS 2016 was $47 \%$ but determinants of use are not available. Moreover information on utilization of modern contraceptive methods among currently married/union women in mid to late reproductive age in the study area is scarce. Women in late reproductive age are more at risk of pregnancy related complications and contraceptive utilization is the best intervention to improve women health.

Therefore our study aimed to assess modern contraceptive utilization and associated factors among married women of middle and late reproductive age in Finote Selam town, northwest Ethiopia.

\section{Methods}

\section{Study design and setting}

A community-based cross-sectional study was conducted from June 30 to July 15, 2017, among married women in Finote Selam town, northwest Ethiopia. Finote
Selam town is located in West Gojam Administration Zone of the Amhara Regional State, in northwest Ethiopia. We selected Finote Selam purposely as it is similar to other towns in the Amhara region in socioeconomic status, education, ethnicity and religion. According to the population projections of Ethiopia for all regions at the district level for 2017, the total population of the town was estimated to be 38,399. Out of these, 19,923 are male and 18,476 female [13]. The town has five kebeles, the smallest administrative units. Based on information obtained from town administrative the total number of households was 5530 .

According to information obtained from the Finote Selam district health office, the district has one primary hospital, one public health centre, four private clinics and five health posts owned by the government. Family planning and maternal health services are provided free of charge in the government health facilities. The sample population for this study was all married women aged 30-49 years living in Finote Selam town.

\section{Sample size and sampling procedure}

The sample size for prevalence of use was determined using a single population proportion formula with the assumptions of $95 \%$ confidence interval, $5 \%$ margin of error, and assuming $47 \%$ used a modern contraceptive in the Amhara region based on the EDHS 2016 [5]. Sample size calculations for assessing factors associated with modern contraceptive utilization [8], assuming a 95\% level of confidence, and $80 \%$ power resulted in a required sample size of 546 , greater than the sample size required for estimating prevalence of use. Assuming 5\% non-response rate and adding two design effects, yielded a sample size of 1146 for this study.

Three of the five kebeles were selected by simple random sampling. A cluster sampling technique was used to ascertain study participants. The total sample size was proportionally allocated to the three cluster kebeles based on the number of households within the kebele: 608, 304 and 234 women were allocated to each selected cluster.

\section{Data collection}

A face-to-face interviewer-administered, structured and pretested questionnaire adapted from a previous study was used [9]. The questionnaires were prepared in English and then translated into Amharic, a local language. The questionnaire consisted of items assessing socio-demographic characteristics, reproductive history, maternal health service utilization, and modern contraceptive history. Six female diploma and two BSc degree graduated midwives who could speak the local Amharic language were recruited for data collection, and supervision, respectively. To ensure data quality, 2 days of training on data collection techniques was given to data collectors and supervisors. Interview was conducted at each study participants home or 
women at shop with in home compound. The data collection and supervision were overseen by researchers to ensure completeness and consistency of data.

\section{Variable definitions}

Modern contraception methods are defined to include female and male sterilization, oral hormonal pills, the intra-uterine device (IUD), male and female condoms, injectables, the implant, vaginal barrier methods and emergency contraception [6].

Antenatal care utilization was defined as having had at least one visit by a skilled provider during the last pregnancy. Postnatal care utilization was defined as having had at least one visit by a health provider during the post-partum period (within 6 weeks after child birth) after the last childbirth.

\section{Data analysis}

The data were checked for completeness, coded manually, and experienced clerks entered data into EPI-info version 7 statistical software. After checking consistency and completeness, data were exported to SPSS version 20 for further analysis. Both bivariate and multivariable logistic regression models were estimated to identify variables associated with modern contraceptive method utilization. All variables with a $p$-value of less than 0.2 in the bivariate analysis were considered for multivariable analysis to control potential confounders. The strength of association was interpreted using adjusted odds ratio with $95 \%$ confidence interval.

\section{Results}

Socio-demographic characteristics of the participants A total of 1134 of the 1146 eligible women were interviewed for this study giving a response rate of $98.9 \%$.
The mean age of the participants was 37.4 years (SD + 5.7 years). Nearly two-thirds (64.9\%) of participants were aged 30-39 years. Orthodox Christians accounted for (92.2\%) of the study participants. Approximately half (45.1\%) of the women had no formal education while $11.5 \%$ had attended college or above. Regarding the occupational status of the participants, $47.8 \%$ were unemployed and $15.1 \%$ were employed in government or private sectors. Nearly $65 \%$ of the participants had an average family monthly income of less than $\$ 68$ US (Table 1).

\section{Reproductive characteristics and use of maternal health services during the last pregnancy}

A total of 1013 (89.3\%) women had a history of at least one pregnancy and $232(20.4 \%)$ had had five or more pregnancies. Among participants who had a history of pregnancy, $582(57.4 \%)$ had had at least one antenatal visit during their last pregnancy. Antenatal care (ANC) visits were frequently conducted at the hospital. Among women with a history of pregnancy 163 (16.3\%) had had at least one abortion. Among women who had experienced an abortion, $75 \%$ and $25 \%$ were spontaneous and induced abortion respectively. Most participants had a history of at least one childbirth (88.2\%) and $19.3 \%$ had had five or more children (Table 2) with $38.4 \%$ having delivered their last child at home.

\section{Modern contraception utilization}

Among the participants, 830 (73\%) ever used any modern contraceptive method. During data collection, 429 (37.8\%) (95\% CI 35.4-40.2) were using any modern contraceptive method currently. The most frequently

Table 1 Socio-demographic characteristics of study participants in Finote Selam town, Northwest Ethiopia, 2017

\begin{tabular}{|c|c|c|c|}
\hline Characteristics & & $\begin{array}{l}\text { Frequency } \\
n=1134\end{array}$ & Percent \\
\hline \multirow[t]{2}{*}{ Age } & 30-39 & 736 & 64.9 \\
\hline & $40-49$ & 396 & 35.1 \\
\hline \multirow[t]{3}{*}{ Religion } & Orthodox & 1046 & 92.2 \\
\hline & Muslim & 80 & 7.1 \\
\hline & Protestant & 8 & 0.7 \\
\hline \multirow[t]{4}{*}{ Educational status } & No formal education & 512 & 45.1 \\
\hline & Primary school & 293 & 25.8 \\
\hline & Secondary school (9-12) & 198 & 17.5 \\
\hline & College/university & 131 & 11.6 \\
\hline \multirow[t]{3}{*}{ Occupational status } & Unemployed & 542 & 47.8 \\
\hline & Self employed & 421 & 37.1 \\
\hline & Government/private employed & 171 & 15.1 \\
\hline \multirow[t]{2}{*}{ Family average monthly income ${ }^{a}$} & $<68$ & 732 & 64.6 \\
\hline & $68+$ & 402 & 35.4 \\
\hline
\end{tabular}

${ }^{\mathrm{a}}$ in US dollars 
Table 2 Reproductive characteristics and use of maternal health services during the last pregnancy among married women in Finote Selam town, northwest Ethiopia, 2017

\begin{tabular}{|c|c|c|c|}
\hline Characteristic & & $\begin{array}{l}\text { Frequency } \\
(N=1134)\end{array}$ & Percent \\
\hline \multirow[t]{2}{*}{ History of pregnancy } & No & 121 & 10.7 \\
\hline & Yes & 1013 & 89.3 \\
\hline \multirow[t]{4}{*}{ Number of previous pregnancies } & 0 & 121 & 10.7 \\
\hline & $1-2$ & 363 & 32 \\
\hline & $3-4$ & 418 & 36.9 \\
\hline & $5+$ & 232 & 20.4 \\
\hline \multirow[t]{2}{*}{ Antenatal Care utilization $(N=1013)$} & No & 431 & 42.6 \\
\hline & Yes & 582 & 57.4 \\
\hline \multirow[t]{2}{*}{ Place of Antenatal Care $(N=582)$} & Health center & 271 & 46.6 \\
\hline & Hospital & 311 & 53.4 \\
\hline \multirow[t]{2}{*}{ History of abortion $(N=1013)$} & No & 850 & 83.9 \\
\hline & Yes & 163 & 16.1 \\
\hline \multirow[t]{2}{*}{ How the termination occurred $(N=163)$} & Spontaneous & 122 & 75 \\
\hline & Induced & 41 & 25 \\
\hline \multirow[t]{2}{*}{ History of child birth } & No & 134 & 11.8 \\
\hline & Yes & 1000 & 88.2 \\
\hline \multirow[t]{4}{*}{ Parity } & 0 & 134 & 11.8 \\
\hline & $1-2$ & 389 & 34.3 \\
\hline & $3-4$ & 392 & 34.6 \\
\hline & $5+$ & 219 & 19.3 \\
\hline \multirow[t]{4}{*}{ Place of delivery last child $N=1000$} & Home & 384 & 38.4 \\
\hline & Health center & 228 & 22.8 \\
\hline & Hospital & 370 & 37 \\
\hline & Others $^{a}$ & 18 & 1.8 \\
\hline \multirow[t]{2}{*}{ Postnatal Care $(N=1000)$} & No & 742 & 74.2 \\
\hline & Yes & 258 & 25.8 \\
\hline \multirow[t]{3}{*}{ Place of Postnatal Care $(N=258)$} & Health center & 145 & 56.2 \\
\hline & hospital & 110 & 42.6 \\
\hline & Private clinic & 3 & 1.2 \\
\hline
\end{tabular}

${ }^{\mathrm{a}}$ Health post and private clinic

used contraceptive method was an injectable contraceptive $(26.5 \%)$ followed by implants $(8 \%)$ with the least used method an intrauterine contraceptive device (IUCD) (0.97\%) (Fig. 1).The major (85\%) source of contraceptives was a public health facility. Among modern contraceptive users, $70.1 \%$ used injectable contraceptives and $21.3 \%$ used implant contraceptive methods whereas oral contraceptive and IUCD were used by $6 \%$ and $2.6 \%$ respectively.

Among women aged 30-39 years, 66\% reported using modern contraceptive methods during the survey, whereas only $31.3 \%$ of women aged $40-49$ were using modern contraceptive methods.

\section{Determinants of modern contraception use}

In the multivariable logistic analysis, higher educational status, lower gravidity, and antenatal care service use were significantly and independently associated with modern contraceptive methods utilization (Table 3).

Women who had attended secondary school were 1.53 times (95\% CI: 1.01-2.24) and who had attended college and above were also 1.51 times (95\% CI: 1.02-2.03) more likely to use modern contraceptive methods than women with no formal education. Null gravida participants were 4.61 times (95\% CI: 3.20-5.52) more likely to use contraceptive methods than women who had had five or more pregnancies. Whereas those with 1-2 pregnancies were 


\section{Percentage}

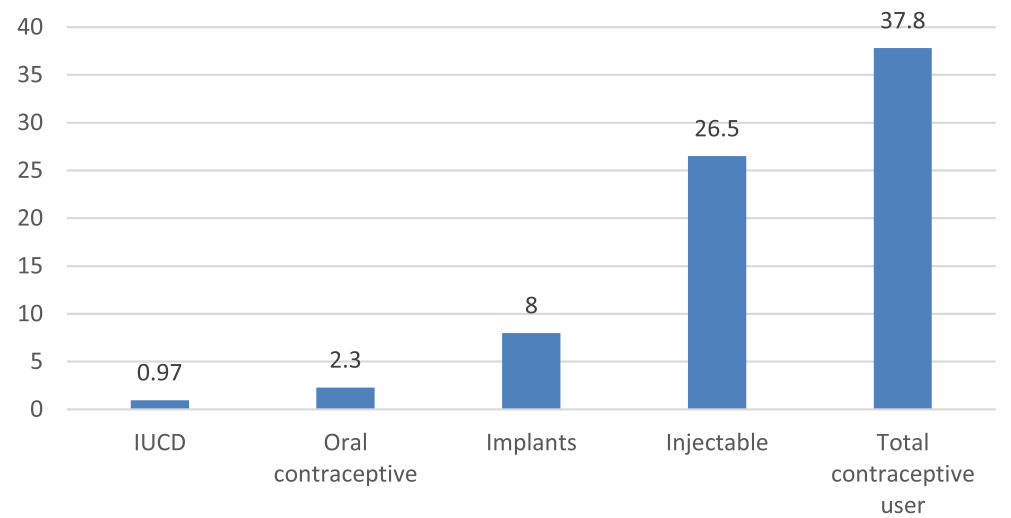

Fig. 1 Proportion using each modern contraceptive method among married or in-union women in Finote Selam town, northwest Ethiopia, 2017

Table 3 Unadjusted and adjusted odds ratios for factors associated with modern contraceptive use among married women in Finote Selam town, northwest Ethiopia, 2017

\begin{tabular}{|c|c|c|c|c|c|}
\hline \multirow[t]{2}{*}{ Factors } & & \multicolumn{2}{|c|}{ Contraceptive utilization } & \multirow{2}{*}{$\begin{array}{l}\text { Unadjusted } \\
\text { OR 95\%Cl }\end{array}$} & \multirow{2}{*}{$\begin{array}{l}\text { Adjusted } \\
\text { OR } 95 \% \mathrm{Cl}\end{array}$} \\
\hline & & No & Yes & & \\
\hline \multirow[t]{2}{*}{ Age } & $30-39$ & $262(44 \%)$ & $333(66 \%)$ & $1.81(1.32-2.54)^{* *}$ & $1.28(0.89-1.86)$ \\
\hline & $40-49$ & 137 (58.7\%) & $96(31.3 \%)$ & 1 & 1 \\
\hline \multirow[t]{4}{*}{ Educational status } & No formal education & $176(57 \%)$ & $132(43 \%)$ & 1 & 1 \\
\hline & Primary school & $118(48.5 \%)$ & $125(51.5 \%)$ & $1.37(1.10-1.98)^{* *}$ & $1.24(0.86-1.78)$ \\
\hline & Secondary school (9-12) & $53(33 \%)$ & 107 (57\%) & $2.69(1.83-4.01)^{* * *}$ & $1.53(1.01-2.24)$ \\
\hline & College/university & $52(44 \%)$ & $65(56 \%)$ & $1.67(1.15-2.55)^{* *}$ & $1.51(1.02-2.03)$ \\
\hline \multirow[t]{3}{*}{ Occupation } & Unemployed & $193(54.8 \%)$ & $159(45.2 \%)$ & 1 & 1 \\
\hline & Self employed & $60(41 \%)$ & $86(59 \%)$ & $1.73(1.13-2.14)^{* *}$ & $1.12(0.65-1.92)$ \\
\hline & Government/private employed & $146(44 \%)$ & $184(56 \%)$ & $1.52\left(1.82-2.53^{* *}\right.$ & $1.31(0.72-2.36)$ \\
\hline \multirow[t]{2}{*}{ History of childbirth } & No & $35(30.7 \%)$ & $79(69.3 \%)$ & 1 & 1 \\
\hline & Yes & $364(51 \%)$ & $350(49 \%)$ & $0.35(0.22-0.55)$ & $0.24(0.09-0.23)$ \\
\hline \multirow[t]{4}{*}{ Number of previous pregnancy } & 0 & $28(27 \%)$ & $76(73 \%)$ & $7.31(4.14-13.21)^{* * *}$ & $4.61(3.20-5.52)^{* * *}$ \\
\hline & $1-2$ & 134 (44\%) & $170(56 \%)$ & $3.40(2.13-5.40)^{* * *}$ & $3.22(2.03-5.44)^{* * *}$ \\
\hline & $3-4$ & $148(49.6 \%)$ & $150(50.4 \%)$ & $2.71(1.70-4.32)^{* * *}$ & $2.33(1.41-3.72)^{* *}$ \\
\hline & $5+$ & 89 (73\%) & $33(27 \%)$ & 1 & 1 \\
\hline \multirow[t]{2}{*}{ Place of ANC } & Health center & $101(44.3 \%)$ & $12,755.7 \%)$ & $1.55(1.13-2.24)^{* *}$ & $1.25(0.92-1.85)$ \\
\hline & Hospital & $148(55 \%)$ & $120(45 \%)$ & 1 & 1 \\
\hline \multirow[t]{2}{*}{ Abortion history } & No & $328(46.5 \%)$ & $376(53.5 \%)$ & 1 & 1 \\
\hline & Yes & $71(57 \%)$ & $53(43 \%)$ & $0.65(0.44-0.95)^{* *}$ & $0.87(0.72-1.12)$ \\
\hline \multirow[t]{2}{*}{ Types of abortion } & Spontaneous & $56(65 \%)$ & $30(35 \%)$ & $0.39(0.17-0.85)^{* *}$ & $0.41(0.18-1.05)$ \\
\hline & Induced & $16(42 \%)$ & $22(58 \%)$ & 1 & 1 \\
\hline \multirow[t]{4}{*}{ Parity } & 0 & 35 (30.7\%) & 79 (69.3\%) & $5.60(3.12-7.81)^{* *}$ & $2.6(0.98-6.79)$ \\
\hline & $1-2$ & $136(42.6 \%)$ & $183(57.4 \%)$ & $3.34(2.11-5.31)^{* * * *}$ & $1.99(0.89-4.17)$ \\
\hline & $3-4$ & $146(52 \%)$ & $134(48 \%)$ & $2.28(1.41-3.60)^{* * * *}$ & $1.7(0.80-3.34)$ \\
\hline & $5+$ & $82(72 \%)$ & $33(28 \%)$ & 1 & 1 \\
\hline \multirow[t]{2}{*}{ PNC } & No & $304(50 \%)$ & $304(50 \%)$ & 1 & 1 \\
\hline & Yes & $95(36.8 \%)$ & $163(63.2 \%)$ & $1.71(1.14-2.16)^{* *}$ & $1.53(1.12-2.10)^{* *}$ \\
\hline
\end{tabular}


3.22 times (95\%CI: 2.03-5.44) and women with 3-4 pregnancies were 2.33 times (95\%CI: 1.41-3.72) more likely to use modern contraceptive methods than women with five or more pregnancies. Women who had postnatal care during the last pregnancy were 1.53 times (95\%CI: 1.01-2.10) more likely to use modern contraceptive methods than women who had not (Table 3). Women's reasons for not using modern contraceptive methods included that they wanted an additional child and fear of side effects of contraceptive methods (Fig. 2).

\section{Discussion}

Family planning services are a cost-effective strategy for preventing more than $20 \%$ of maternal mortality and $17 \%$ of neonatal mortality by preventing risky and unwanted pregnancy [4]. Use of modern contraceptive methods are especially important to decrease maternal mortality at the two extremes of reproductive age ( $<20$ years and $>40$ years); however the use of modern contraceptive methods among late reproductive age women is low. Therefore the present study assessed modern contraceptive utilization and associated factors among married women in middle and late reproductive age living in Finote Selam town, northwest Ethiopia.

The findings of this study showed that $37.8 \%$ of the participants, were currently using modern contraceptive method which is comparable to the 2016 EDHS that reported 35\% [6], and the Kersa Demographic and Health Surveillance System of Ethiopia that reported 40\% [14]. This utilization is higher than that reported from the Afar region of Ethiopia 20.8\% [15], and in rural Mozambique 23\% [16]. However, it is lower than that reported from 2016 EDHS Amhara region 47\% [6], Kenya 68.2\% [17], western Ethiopia 71.9\% [7], and urban Kenya $65 \%$ [18]. Among the total study participants, $26.5 \%$ and $8 \%$ were using injectable and implants contraceptive methods respectively. According to the 2016 EDHS the most commonly used methods were also injectable(23\%) and implants(8\%) [6]. Studies conducted in the other parts of Ethiopia also found that the most commonly used methods among contraceptive user were injectables (78\%) and implants $(20 \%)$ [8, 19], consistent with our findings among contraceptive users.

Previous studies found that women in late reproductive age use modern contraceptive method less than young and middle aged women [12], however age was not independently associated with modern contraceptive use in this study. In our study, women who had secondary school or higher were more likely to use modern contraception methods than those who had no a formal education similar with findings reported in from other studies [8, 19-21]. Our finding suggest that women's previous pregnancy history was associated with likelihood of modern contraceptive utilization, as nulligravid participants were much more likely to use a modern contraceptive method compared to grand multiparous women. Similar findings were reported in Ethiopian Demographic Health Survey (EDHS 2016) [6].

Antenatal care service utilization and institutional delivery during the last pregnancy were not found to be significantly associated with modern contraceptive utilization in our study. This result is inconsistent with another Ethiopian study, which reported that women who uses antenatal care services and a health facility delivery during the last pregnancy were more likely to use modern contraceptive methods than women who had not used antenatal care [22]. We identified that participants who had utilized postnatal care following their last childbirth were more likely to use any modern contraception methods than women who did not have a postnatal follow-up. This finding is supported by other studies [19, 23].

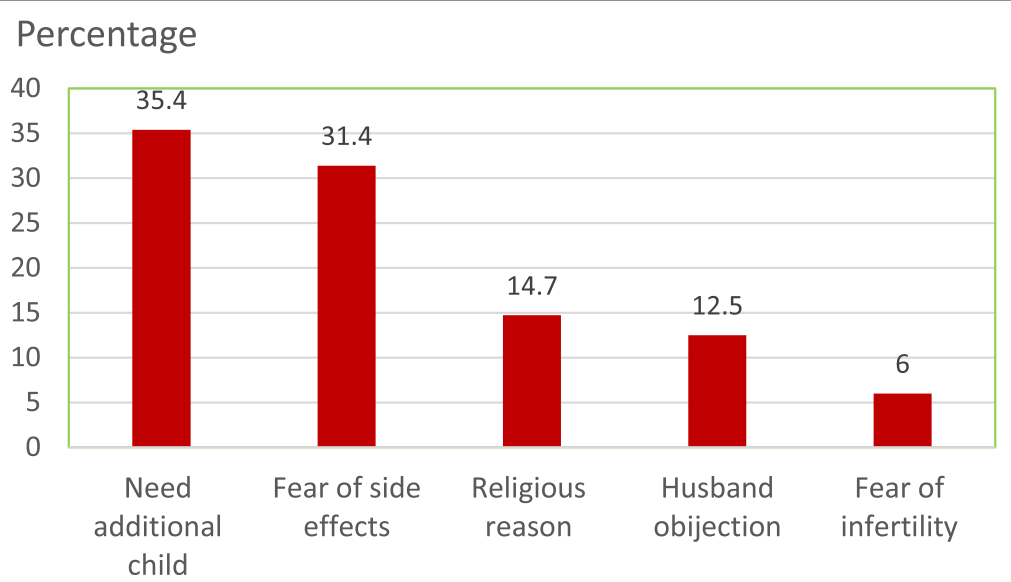

Fig. 2 Major reason women were not using a modern contraceptive method among married or in-union women in Finote Selam town, northwest Ethiopia, 2017 
Reasons that women reported for not using modern contraceptives in our study, including the need an additional child and fear of contraceptive side effects are similar to those reported in north Shoa Ethiopia [9] and Nigeria [11].

Limitations of this study include that the study was carried out in an urban setting and may not be representative of rural women, however, we did include a semi-urban kebele. We have selected Finote Selam purposely, regarding characteristics of the population: socioeconomic status, education, ethnicity and religion it is similar with other towns in the Amhara region of Ethiopia; however, there is a difference with other towns outside Amhara region especially in less developed regions of Ethiopia. Thus our finding is possible to generalize regarding modern contraceptives used among middle and late reproductive age women in the Amhara region in Ethiopia rather than Ethiopia as a whole. Also male involvement was not considered as a determinant in contraceptive utilization.

\section{Conclusion}

This study documented that modern contraceptive utilization among women age 30-49 is low in Finote Selam town Northwest Ethiopia. Increasing women's educational status, lower number of previous pregnancies and postnatal care service utilization during their last birth were significantly and positively associated with modern contraceptive method use. Providing modern contraceptive services targeting grand multiparous women and women who have no formal education, using community health workers is important. Improving postnatal care utilization is another important strategy to enhance modern contraceptive method uptake.

\section{Abbreviations}

ANC: Ante Natal care; AOR: Adjusted Odds Ratio; Cl: Confidence Interval; PNC: Post Natal care; SD: Standard Deviation; SPSS: Statistical Package for Social Sciences

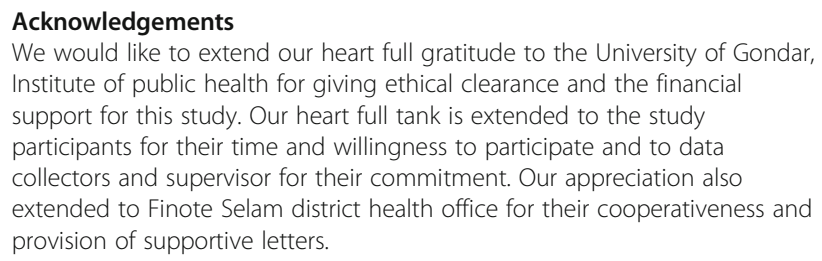
Institute of public health for giving ethical clearance and the financial support for this study. Our heart full tank is extended to the study participants for their time and willingness to participate and to data collectors and supervisor for their commitment. Our appreciation also extended to Finote Selam district health office for their cooperativeness and provision of supportive letters.

\section{Funding}

The University of Gondar sponsored this study. However, it has no role in decision to publish, manuscript preparation and publication.

\section{Availability of data and materials}

All the required data are available in the main document.

\section{Authors' contributions}

ABG brought the idea. $A B G, A A G$, equally contributed to proposal development, data collection process, data management and analysis, and write up. Both authors have read and approved the manuscript.

\section{Ethics approval and consent to participate}

Ethical approval was obtained from Institutional Review Board of the University of Gondar, Institute of Public Health. Participants were informed about the confidentiality of information and it was maintained by excluding personal identifiers from the data collection form. Verbal informed consent was obtained from every study participants before data collection. Participants were informed that participation was voluntary and as it was their right not to participate or withdraw at any time if they were not comfortable.

\section{Consent for publication}

It is not applicable since it is a cross-sectional study.

\section{Competing interests}

The authors declare that they have no any competing interests.

\section{Publisher's Note}

Springer Nature remains neutral with regard to jurisdictional claims in published maps and institutional affiliations.

Received: 13 December 2017 Accepted: 9 October 2018

Published online: 19 October 2018

\section{References}

1. Hubacher D, Trussell J. A definition of modern contraceptive methods. Contraception. 2015;92:420-1.

2. Life Y: GLOBAL PERSPECTIVES ON UNPLANNED PREGNANCIES. 2017.

3. Lu MC. Recommendations for preconception care. Am Fam Physician. 2007; 76(3):397-400.

4. Fauveau V, Wojtyniak B, Chakraborty J, Sarder AM, Briend A. The effect of maternal and child health and family planning services on mortality: is prevention enough? BMJ. 1990;301:103-7.

5. Curtis KM. US selected practice recommendations for contraceptive use, 2016. MMWR Recommendations and Reports, vol. 65; 2016

6. ETHIOPIA FDROE. Demographic and health survey 2016. Rockville: Central Statistical Agency Addis Ababa, Ethiopia; 2017

7. Ahmed S, Creanga AA, Gillespie DG, Tsui AO. Economic status, education and empowerment: implications for maternal health service utilization in developing countries. PLoS One. 2010;5:e11190.

8. Tekelab T, Melka AS, Wirtu D. Predictors of modern contraceptive methods use among married women of reproductive age groups in Western Ethiopia: a community based cross-sectional study. BMC Womens Health. 2015;15:52.

9. Mohammed A, Woldeyohannes D, Feleke A, Megabiaw B. Determinants of modern contraceptive utilization among married women of reproductive age group in north Shoa zone, Amhara region, Ethiopia. Reprod Health. 2014;11:13.

10. Tilahun T, Coene G, Luchters S, Kassahun W, Leye E, Temmerman M, Degomme O. Family planning knowledge, attitude and practice among married couples in Jimma zone, Ethiopia. PLoS One. 2013;8:e61335.

11. Rabiu A, Abubakar IS, Garba I, Haruna IU. Contraceptive choices among grand multiparous women at Murtala Mohammed specialist hospital, Kano. Ann Afr Med. 2016;15:58-62.

12. Muyindike W, Fatch R, Steinfield R, Matthews LT, Musinguzi N, Emenyonu $\mathrm{NI}$, Martin JN, Hahn JA. Contraceptive use and associated factors among women enrolling into HIV care in southwestern Uganda. Infect Dis Obstet Gynecol. 2012;2012:340782.

13. Federal Demographic Republic of Ethiopia CSA, Addis Ababa, Ethiopia: Population projection of Ethiopia for all regions at Wereda level from 2014 - 2017.

14. Musa A, Assefa N, Weldegebreal F, Mitiku H, Teklemariam Z. Factor associated with experience of modern contraceptive use before pregnancy among women who gave birth in Kersa HDSS, Ethiopia. BMC Public Health. 2016;16:614.

15. Belda SS, Haile MT, Melku AT, Tololu AK. Modern contraceptive utilization and associated factors among married pastoralist women in bale ecoregion, bale zone, south East Ethiopia. BMC Health Serv Res. 2017;17:194

16. Agadjanian V, Hayford SR, Luz L, Yao J. Bridging user and provider perspectives: family planning access and utilization in rural Mozambique. Int J Gynaecol Obstet. 2015;130 Suppl 3:E47-51. 
17. Ngugi EW, Kim AA, Nyoka R, Ng'ang'a L, Mukui I, Ng'eno B, Rutherford GW Contraceptive practices and fertility desires among HIV-infected and uninfected women in Kenya: results from a nationally representative study. $J$ Acquir Immune Defic Syndr. 2014;66(Suppl 1):S75-81.

18. Tumlinson K, Pence BW, Curtis SL, Marshall SW, Speizer IS. Quality of care and contraceptive use in urban Kenya. Int Perspect Sex Reprod Health. 2015;41:69-79

19. Abraha TH, Teferra AS, Gelagay AA. Postpartum modern contraceptive use in northern Ethiopia: prevalence and associated factors. Epidemiology and health. 2017;39:e2017012.

20. Asiimwe JB, Ndugga P, Mushomi J, Manyenye Ntozi JP. Factors associated with modern contraceptive use among young and older women in Uganda; a comparative analysis. BMC Public Health. 2014;14:926.

21. Mekonnen W, Worku A. Determinants of low family planning use and high unmet need in butajira district. South Central Ethiopia. Reprod Health. 2011:8:37.

22. Abera Y, Mengesha ZB, Tessema GA. Postpartum contraceptive use in Gondar town, Northwest Ethiopia: a community based cross-sectional study. BMC Womens Health. 2015;15:19.

23. Mengesha ZB, Worku AG, Feleke SA. Contraceptive adoption in the extended postpartum period is low in Northwest Ethiopia. BMC Pregnancy Childbirth. 2015;15:160

Ready to submit your research? Choose BMC and benefit from:

- fast, convenient online submission

- thorough peer review by experienced researchers in your field

- rapid publication on acceptance

- support for research data, including large and complex data types

- gold Open Access which fosters wider collaboration and increased citations

- maximum visibility for your research: over $100 \mathrm{M}$ website views per year

At $\mathrm{BMC}$, research is always in progress.

Learn more biomedcentral.com/submissions 